\title{
Unilateral adrenal infarction in pregnancy
}

\author{
Paul-Ann D Green, ${ }^{1}$ Ivan M Ngai, ${ }^{1}$ Tony T Lee, ${ }^{2}$ David J Garry ${ }^{1}$
}

1 Department of OB-GYN and Women's Health, Albert Einstein College of Medicine/ Montefiore Medical Center, Bronx, New York, USA 2Department of Radiology, Albert Einstein College of Medicine/Montefiore Medical Center, Bronx, New York, USA

Correspondence to Professor David I Garry, dgarry@montefiore.org
To cite: Green P-AD, Ngai IM, Lee TT, et al. BMJ Case Rep Published online: [please include Day Month Year] doi:10.1136/bcr-2013009997

\section{SUMMARY}

A 25-year-old pregnant woman at 28 weeks gestational age presented with increasing abdominal pain and was found to have a unilateral adrenal infarction on a CT scan of the abdomen. Her medical history was unremarkable. There was no evidence of adrenal insufficiency with normal cortisol and adenocorticotropic hormone levels for pregnancy. Evaluation of thrombophilia disorders established the patient to be heterozygous for methylenetetrahydrofolatereductase C677T gene mutation as the only finding. The patient was anticoagulated to prevent contralateral thrombosis. At 32 weeks she experienced spontaneous rupture of membranes. One week later she delivered vaginally and remained anticoagulated for the puerperium.

\section{BACKGROUND}

Methylenetetrahydrofolatereductase (MTHFR) is an enzyme that facilitates the conversion of 5,10-methylenetetrahydrofolate to 5methyltetrahydrofolate, with nicotinamide adenine dinucliotide phosphate and riboflavin, the vitamin, as cofactors. ${ }^{1}$ MTHFR C677T genetic polymorphism was first described with an associated cardiovascular disease in 1988 , by Kang et al. ${ }^{2}$ This mutation results in an amino acid substitution of valine to alanine at the position 677 of the protein and is associated with an increase in homocysteine concentrations, and lower MTHFR enzyme concentrations. $^{3} 4$ Although, hyperhomocysteninemia was thought of as a risk factor for deep venous thrombosis in the past. ${ }^{5}$ Newer studies have not shown an association of increased risk of venous thromboembolic disease with mutations of the C677T MTHFR gene, and plasma homocysteine levels. ${ }^{6}$ Nor does screening for the MTHFR mutation appear to identify women at increased risk of maternal thromboembolic events. ${ }^{7}$

We present a rare case of a 28 -week pregnant woman, with no history of prior thrombotic events, presenting with right upper quadrant abdominal pain and subsequently diagnosed with a unilateral right adrenal infarct. A thrombophilia workup demonstrated the patient to be heterozygous for MTHFR C677T gene mutation.

\section{CASE PRESENTATION}

A 25-year-old Hispanic woman para 0-0-2-0 with a history of cervical insufficiency and a McDonald cervical cerclage in situ, presented at 28 weeks gestation, having new onset right upper quadrant pain that started at midnight prior to her presentation. The pain was constant with intermittent worsening in the right upper quadrant and radiation to her right flank. The patient initially believed the pain was secondary to fetal positioning, but as the pain intensified she began having nausea with vomiting and sought medical care. She denied any fever, chills or change in appetite.

The patient's medical history was unremarkable. Her obstetrical history included a 6-week spontaneous pregnancy loss and a 19 week spontaneous pregnancy loss. With the second trimester loss she had presented with pelvic pressure and was found to be $4 \mathrm{~cm}$ cervical dilation with bulging membranes. She progressed and delivered at our institution with cervical insufficiency diagnosed. In this gestation, a history indicated cervical cerclage was placed at 13-weeks gestational age.

On presentation to the hospital, her blood pressure was 114/56 $\mathrm{mm} \mathrm{Hg}$, pulse $103 \mathrm{bpm}$, respiratory rate 20 breaths $/ \mathrm{min}$, temperature $97.7^{\circ} \mathrm{F}$ and a body mass index of $40 \mathrm{~kg} / \mathrm{m}^{2}$. Her oxygen saturation was $100 \%$ on room air. On physical examination, the patient appeared uncomfortable and was writhing on bed. Her abdomen was soft, obese, with no fundal tenderness on uterine palpation. There was moderate tenderness on palpation of the right upper quadrant under her rib cage, with mild rebound but no guarding. Bowel sounds were present and normal. The patient was admitted to the hospital and initially managed with fluid hydration, antacids and intravenous narcotic analgesia. This provided minimal relief to the patient.

\section{INVESTIGATIONS}

An abdominal and right upper quadrant ultrasound was performed which did not visualise the appendix, but was significant for no gallstones, biliary dilation nor hydronephrosis. A complete set of labs were sent which were remarkable only for a white cell count $22.5 \mathrm{~K} / \mu \mathrm{L}$ with $83 \%$ granulocytes. Surgical consultation recommended a CT of the abdomen to evaluate for possible appendicitis. CT of the abdomen revealed an enlarged right adrenal gland with decreased enhancement and adjacent inflammatory changes suggestive of an infarct, with a normal-appearing appendix (figure 1). Left adrenal gland was normal. The radiology attending was promptly contacted, and described that CT was of good quality, with no anomalous vasculature seen on the study, and an MRI was not likely to add any information.

Cortisol levels and adenocortocotropic hormone (ACTH) levels were obtained to assess for adrenal insufficiency and a mildly elevated cortisol level of $36 \mu \mathrm{g} / \mathrm{dL}$ was noted with a normal ACTH result of $32 \mathrm{pg} / \mathrm{mL}$. A workup included thrombophilia disorders that included factor $\mathrm{V}$ Leiden, prothrombin mutation and MTHFR and acquired thrombophilias including antiphospholipid panel, protein C, protein S, antithrombin III and annexin A5 antibodies. The only significant result was heterozygote for MTHFR C677T polymorphism gene mutation. 


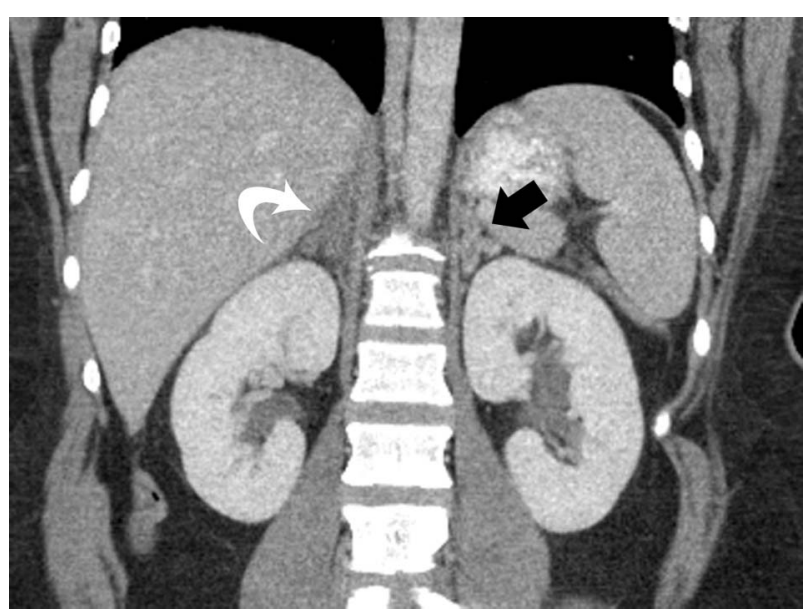

Figure 1 Coronal reconstructed CT with contrast of the abdomen. The adrenal glands are inverted ' $V$ '-shaped organs located above each kidney. The infarcted right adrenal gland (white arrow) is enlarged and decreased in enhancement compared to the normal left adrenal gland (black arrow).

\author{
DIFFERENTIAL DIAGNOSIS \\ - Renal colic \\ - Mesenteric infarction \\ - Pregnancy associated (ie, labour associated, fibroids, etc) \\ - Cholelithiasis/pancreatitis \\ - Liver associated (ie, infarction, haemorrhage, etc) \\ - Appendicitis
}

\section{TREATMENT}

Intravenous anticoagulation with unfractionated heparin drip was initiated to reduce the risk of another infarct in the contralateral adrenal gland. After several days, the patient was transitioned to low-molecular-weight heparin and discharged home for outpatient antepartum care.

\section{OUTCOME AND FOLLOW-UP}

The patient re-presented to our institution at 32 weeks with a diagnosis of preterm premature rupture of membranes. At the time of evaluation, there was reassuring fetal heart monitoring with no uterine contractile activity and the patient showed no evidence of chorioamnionitis; therefore, latency antibiotics were administered, the McDonald cervical cerclage was left in situ, and corticosteroids were administered for improved fetal outcome should delivery occur. The patient remained on intravenous unfractionated heparin during her antepartum admission. The cervical cerclage was removed at 33 weeks gestational age secondary to uterine contractions, preterm labour. Heparin was discontinued during labour.

A live, $2180 \mathrm{~g}$ male infant was delivered vaginally with Apgar scores of 9 at $1 \mathrm{~min}$ and 9 at $5 \mathrm{~min}$. The intravenous heparin was restarted $4 \mathrm{~h}$ after delivery. Postdelivery, the patient was placed of low-molecular-weight heparin at a full anticoagulation dosage for 6 weeks postpartum. She was scheduled for a postpartum visit and outpatient follow-up with haematology. The patient had declined Coumadin conversion and desired to remain on low-molecular-weight heparin for puerperium. The placental pathology was significant for chorioamnionitis and a partial placental abruption.

\section{DISCUSSION}

Adrenal infarction is a very rare event with only one reported case occurring during pregnancy, Riddell and Khalili ${ }^{8}$ appeared in the literature which was associated with antiphospholipid syndrome. Adrenal infarction can present with abdominal pain, nausea and vomiting secondary to electrolyte disturbances. The adrenal glands are endocrine glands located in the retroperitoneum superior to the kidneys and responsible for releasing hormones in response to stress as well as producing androgens. The stress response is through the synthesis of corticosteroids and catecholamines. Literature supports evaluation with CT or MRI to make a diagnosis of a suspected adrenal infarction or haemorrhage. ${ }^{8}$ The use of gadolinium has been considered a contraindication in pregnancy, thus a non-contrast MRI would not have been as sensitive as a contrast-enhanced CT for detection of adrenal infarct in the absence of haemorrhage. Once a diagnosis of adrenal infarct is made, therapeutic anticoagulation therapy is recommended to prevent contralateral adrenal infarction. The risks of anticoagulation need to be considered, especially haemorrhage, in the setting of pregnancy due to potential complications with regional anaesthesia or bleeding related to vaginal or caesarean delivery. In our patient, after reviewing the images with the radiologist, there was no evidence of adrenal haemorrhage and the patient could be started on therapeutic anticoagulation. We recommend a multidisciplinary, patient tailored approach when deciding to anticoagulate involving obstetricians, anaesthesiologists, nursing and medical subspecialists.

Adrenal infarction has typically been seen in conjunction with haemorrhage in the setting of adrenal insufficiency and has been described as the initial presentation of antiphospholipid syndrome. ${ }^{9}$ When adrenal infarction occurs, the majority are bilateral and typically associated with shock, secondary to acute adrenal insufficiency. Our patient presented with increasing abdominal pain and was diagnosed after CT imaging while evaluating the appendix. The finding of MTHFR C677T allele heterozygosity coupled with the hypercoaguable state associated with pregnancy may account for the unilateral adrenal infarct. The patient avoided adrenal insufficiency secondary to the contralateral adrenal gland remaining unaffected. Recently, Mendonca et $a l^{10}$ reported a male patient diagnosed as a heterozygote for MTHFR $677 \mathrm{~T}$ who had presented with a right kidney vascular infarct. The clinical significance $677 \mathrm{CT}$ mutation is not completely understood and the literature remains controversial about the relation between the mutation and thrombosis. $^{11}$

Although our patient did not have adrenal insufficiency, the diagnosis during pregnancy can be challenging and requires a great degree of clinical suspicion. Cortisol physiology during pregnancy results in both total and free cortisol levels increasing throughout the gestation. The increased oestrogen in pregnancy stimulates hepatic corticosteroid-binding globulin production that then decreases free cortisol levels transiently. This results in an increase in pituitary ACTH production to increase free cortisol levels, which rise into the third trimester. The diagnosis of adrenal insufficiency requires: (1) demonstrating low serum cortisol levels; (2) determining if the cortisol deficiency is dependent on or independent of an ACTH deficiency and assessing mineralocorticoid secretion in patients without ACTH deficiency; and (3) finding a treatable cause of the primary disorder. $^{12}$ When the clinical suspicion for adrenal crisis is high, samples for serum cortisol and ACTH levels can be obtained. The use of random serum cortisol and urinary free cortisol levels are unreliable in the diagnosis in pregnancy due to the increasing levels throughout gestation. ${ }^{13}$ A basal morning serum cortisol $<3 \mu \mathrm{g} / \mathrm{dL}$ suggests the diagnosis of adrenal insufficiency in pregnancy. ${ }^{14}$ Based on Jung et al, ${ }^{13}$ basal morning serum cortisol levels of $<11,<16.3$ and $<22 \mu \mathrm{g} / \mathrm{dL}$ during the first, 
second and third trimesters, respectively, should prompt further work-up for possible adrenal insufficiency. Plasma ACTH levels exceeding $100 \mathrm{pg} / \mathrm{mL}$ has been described as consistent with primary adrenal insufficiency, even in late pregnancy. ${ }^{13}$

\section{Learning points}

- Unilateral adrenal infarction is a rare event, especially in pregnancy.

- CT imaging may be used to diagnosis adrenal infarction in pregnancy.

- Anticoagulation for an adrenal gland infarction in the absence of haemorrhage is recommended.

- A hypercoagulable state, such as pregnancy, in patients with methylenetetrahydrofolatereductase (MTHFR) heterozygote for C677T may increase the risk of a thrombotic event.

Contributors P-ADG, and IMN were invoved with direct patient care and intellectual content of the manuscript. TTL and DJG were involved in conception, intellectual content and approval of the final manuscript.

Competing interests None.

Patient consent Obtained.

Provenance and peer review Not commissioned; externally peer reviewed.

\section{REFERENCES}

1 van der Put NM, Gabreëls F, Stevens EM, et al. A second common mutation in the methylenetetrahydrofolatereductase gene: an additional risk factor for neural-tube defects? Am J Hum Genet 1998;62:1044-51.
2 Kang SS, Wong PW, Zhou JM, et al. Thermolabilemethylenetetrahydrofolatereductase in patients with coronary artery disease. Metabolism 1988;37:611-13.

3 Bailey LB, Gregory JF III. Polymorphisms of methylenetetrahydrofolatereductase and other enzymes: metabolic significance, risks and impact on folate requirement. J Nutr 1999:129:919-22.

4 Khandanpour N, Willis G, Meyer FJ, et al. Peripheral arterial disease and methylenetetrahydrofolatereductase (MTHFR) C677T mutations: a case-control study and meta-analysis. J Vasc Surg 2009;49:711-18.

5 Den Heijer M, Koster R, Blom HJ, et al. Hyperhomocysteinemia as a risk factor for deep-vein thrombosis. N Engl J Med 1998;334:759-62.

6 Domagala TB, Adamek L, Nizankowska E, et al. Mutations C677T and A1298C of the 5,10-methylenetetrahydrofolate reductase gene and fasting plasma homocysteine levels are not associated with the increased risk of venous thromboembolic disease. Blood Coagul Fibrinolysis 2002:13:423-31.

7 McColl MD, Ellison J, Reid F, et al. Prothrombin $20210 \mathrm{G} \rightarrow$ A, MTHFR C677T mutations in women with venous thromboembolism associated with pregnancy. BJOG 2000;107:565-9.

8 Riddell AM, Khalali K. Sequential adrenal infarction without MRI-detectable hemorrhage in primary antiphospholipid antibody syndrome. AJR Am J Roentgenol 2004; 183:220-2.

9 Satta MA, Corsello SM, Della Casa S, et al. Adrenal insufficiency as the first clinical manifestation of the primary antiphospholipid antibody syndrome. Clin Endocrinol 2000;52:123-6

10 Mendonca S, Gupta D, Gupta A. Segmental renal artery thrombosis secondary to methylene tetrahydrofolateredutase mutation: an unusual presentation. Iran J Kidney Dis 2012;6:464-6.

11 Pfurtscheller $\mathrm{K}$, Senning B, Bernhard $\mathrm{H}$, et al. Malignant stroke in an adolescent with a homozygous MTHFR 677CT mutation and intake of hormonal contraceptives. Hamostaseologie 2009;29(Suppl 1):S84-6.

12 Yuen KC, Chong LE, Koch CA. Adrenal insufficiency in pregnancy: challenging issues in diagnosis and management. Endocrine. Published Online First: 2 Feb 2013. doi:10.1007/s12020-013-9893-2

13 Jung C, Ho JT, Torpy DJ, et al. A longitudinal study of plasma and urinary cortisol in pregnancy and postpartum. J Clin Endocrinol Metab 2011;96:1533-40.

14 Lebbe M, Arlt W. What is the best diagnostic and therapeutic management strategy for an Addison patient during pregnancy? Clin Endocrinol (Oxf) 2013;78:497-502.

Copyright 2013 BMJ Publishing Group. All rights reserved. For permission to reuse any of this content visit http://group.bmj.com/group/rights-licensing/permissions.

BMJ Case Report Fellows may re-use this article for personal use and teaching without any further permission.

Become a Fellow of BMJ Case Reports today and you can:

- Submit as many cases as you like

- Enjoy fast sympathetic peer review and rapid publication of accepted articles

- Access all the published articles

- Re-use any of the published material for personal use and teaching without further permission

For information on Institutional Fellowships contact consortiasales@bmjgroup.com

Visit casereports.bmj.com for more articles like this and to become a Fellow 